\title{
Job Satisfaction and Mental Health among Physicians in Primary Health Care Centers in Kuwait
}

\author{
Rihab Al-Wotayan', Mahmoud Annaka2 (D), Maqsood Nazar ${ }^{2}$ \\ ${ }^{1}$ Central Department of Primary Health Care, Ministry of Health, Kuwait \\ ${ }^{2}$ Statistics and Indicators Office, Central Department of PHC, Ministry of Health, Kuwait \\ Email: statphc@gmail.com
}

How to cite this paper: Al-Wotayan, R., Annaka, M. and Nazar, M. (2019) Job Satisfaction and Mental Health among Physicians in Primary Health Care Centers in Kuwait. Health, 11, 692-710.

https://doi.org/10.4236/health.2019.116058

Received: January 28, 2019

Accepted: June 7, 2019

Published: June 10, 2019

Copyright (๑) 2019 by author(s) and Scientific Research Publishing Inc. This work is licensed under the Creative Commons Attribution International License (CC BY 4.0).

http://creativecommons.org/licenses/by/4.0/

\section{(c) (i) Open Access}

\begin{abstract}
Objectives: To measure the level of job satisfaction among primary health care physicians Ministry of Health (MOH) Primary Healthcare Center (PHC) physicians, to evaluate the physicians' mental health, and to assess their associated factors. Study Setting: Kuwait Ministry of Health, Primary Care Centers. Study Design: Cross-sectional study. Data Collection: The study was conducted from July to September, 2017. Of 746 questionnaires distributed to all PHC physicians in the $\mathrm{MOH}, 417$ questionnaires were completed. Information was collected on socio-demographic characteristics, work and health-related factors, job satisfaction (using the Warr-Cook-Wall job satisfaction scale), and mental health (using General Health Questionnaire). Principal Findings: Of participants, $40.8 \%$ were male, and $24.9 \%$ were $\mathrm{Ku}-$ waitis. Median overall job satisfaction was $71.4 \%$. There were significant differences in overall job satisfaction with the physician rank $(\mathrm{p}=0.008)$ and governorate $(\mathrm{p}=0.05)$. The GPs were moderately satisfied with work surroundings; work freedom; recognition; degree of responsibility; salary; opportunity to use abilities; attention given to suggestions; relationship with hospital physicians, colleagues, and fellow workers; relations between management and workers; working hours; and the amount of variety in their job, but more satisfied with their immediate supervisors. Conclusions: Job satisfaction of PHC physicians is critical for the improvement of health systems. This study showed that GPs (General Practitioners) were more satisfied overall than previously reported studies done in Kuwait. They were moderately satisfied with their salary and the amount of variety in work.
\end{abstract}

\section{Keywords}

Physicians, Job Satisfaction, Primary Health Care Centers, Kuwait 


\section{Introduction}

There is a documented impact of physician satisfaction on multiple aspects of healthcare delivery. It has been shown that improved job satisfaction of employees is an important factor affecting productivity and results in optimized productivity. Physicians in health care delivery systems while working in highly stressful environment are expected to provide quality patient care. The World Health Organization (WHO) has also recognized the importance of primary health caregivers in 1978 in Alma Ata Declaration [1]. Primary care teams' job satisfaction is an important issue in quality of care for a number of reasons. Poor satisfaction is associated with suboptimal healthcare delivery and poor clinical outcomes, for instance, due to adverse events and reduced patient adherence [2]. For the healthcare workers themselves, lowered job satisfaction is also associated with higher levels of stress and burnout. The Commonwealth Fund surveyed GPs from 7 countries to compare different aspects of work and showed that German GPs have the highest workload and were most dissatisfied compared to their colleagues from other countries [3]. It is known that working conditions have an important impact on job satisfaction and a high workload is associated with a lower performance at primary care practices [4]. Several studies have shown a positive relationship between higher physician satisfaction and patient satisfaction and outcomes [5].

There is some evidence that higher job satisfaction is associated with lower likelihood of patient errors and suboptimal patient care [6]. The work overload was found to be a barrier for providing promotive and preventive activities which are the main elements of PHC services. The MEMO study has shown that workload and lack of adequate resources are relevant factors influencing physician's stress levels. In addition, time pressure due to workload is a crucial issue that physicians may face during patients visits contributes to low job satisfaction [7]. Patients cared for by satisfied physicians declare more trust and confidence in their physicians, have better continuity, higher ratings of their care, lower no-show rates, and enhanced adherence to their medical care [8]. Not surprisingly, dissatisfied physicians are less likely to recommend to medical students that they pursue their specialty [9]. Moreover low physician satisfaction is associated with self-reported psychiatric symptoms and poorer perceived mental health.

Physician satisfaction can be influenced by factors intrinsic to the individual physician (age, gender, race, and specialty) and extrinsic to the physician (work environment, practice setting, patient characteristics, and income) [10]. The job satisfaction of the primary health care physician is a critical factor for health systems because the primary care level is responsible for providing medical care to a greater proportion of the population than any other care level. Also, job satisfaction levels could be related to the quality and efficiency of the care given [11]. Primary health caregivers are responsible for providing medical care to a larger amount of population. They play a pivotal role in treatment timing and in 
health services in general. Medical care can be improved by providing the primary health caregivers with proper working conditions, improved pay scales and other working environment facilities at their peripheral workplace [12]. A study conducted in Madinah Al-Munawwara including 445 health care providers, job dissatisfaction was highly encountered and it was revealed that $52.4 \%$ of physicians were dissatisfied. Professional opportunities, patient care and financial reward were the most frequently encountered domains with which physicians were dissatisfied [13]. Tremendous pressure is being put on primary care physicians in terms of high patient volume, antisocial working hours, demoralization, rising expectations of patients, strained relationships with superiors and colleagues at the hospital, and lack of career trajectories. It seems that many of these negative feelings are also echoed by primary care physicians in other countries in the west [14]. Importantly, physician satisfaction appears to benefit patients. Several studies show a positive relationship between higher physician satisfaction and patient satisfaction and outcomes [15].

The social structure of Kuwaiti society is unique in many ways. Kuwait is a small country. The total area of Kuwait is $17,820 \mathrm{~km}^{2}\left(6880 \mathrm{mi}^{2}\right)$ according to the United Nations Statistics Division. In spite of the small population, estimated to be 1,321,593 local Kuwaiti citizens are only a fraction of the population of 4.330308 million (about 30.5\%). The rest is expatriate workers who are brought to Kuwait to work on a contract basis and their dependents, many of them for an extended period of several years. Factors affecting job satisfaction among physicians include both physician's factors as age, gender, race, and specialty, and job factors as work environment, practice setting, job demands, patient characteristics, collegial support, income, and incentives. The majority of factors associated with satisfaction are modifiable.

The objectives of our study were to evaluate the level of job satisfaction among primary health care physicians working in primary health care centers in Kuwait and to determine the relationships between overall job satisfaction and physicians' socio-demographic characteristics (age, nationality, gender, marital status, monthly income, working experience, location of job area and residence etc.), work and health-related factors. Also measure the mental health score of primary health care physicians working in primary health care centers in Kuwait and its association with socio-demographic, health and work-related factors.

\section{Subjects and Methods}

This cross-sectional study intended to cover all the general practitioner physicians working in Ministry of Health, Primary Health Care Centers in the State of Kuwait. For this study, an English language questionnaire was prepared to be self-administered. All participants completed the same written questionnaire.

The aim of the study was to identify the main sources of job stressors and satisfaction among the Kuwaiti and non-Kuwaiti primary health care physicians working in the primary health care centers in Kuwait and also to explore the 
gender differences in the nature of occupational stressors and satisfaction among the same group of people. The study was conducted between July and November 2016. We distributed 746 questionnaires to GP physicians working in primary health care centers in five health regions in Kuwait. The response rate was (417/746) 55.9\%.

\section{Ethical Considerations}

The study was approved by the Standing Committee for Coordination of Health and Medical Research, Ministry of Health, Kuwait. The study adhered to the principles of the Helsinki Declaration. Written informed consent was obtained from each participant prior to data collection.

\section{Questionnaire}

The questionnaire consisted of 5 parts: 1) Socio-demographic characteristics, 2) Work-related factors, 3) Health-related factors, 4) The Warr-Cook-Wall job satisfaction questionnaire, 5) GHQ-12, Mental Health (General Health Questionnaire-12), Socio-demographic characteristics included information about gender, age, nationality, marital status, monthly income, highest degree, rank (job's position), family history, smoking habits, weight, height and area of job and residence. The work related questions had the information about the years of working experience, daily and weekly working hours with the number of patients examined at their practice and the details about on-call duties. Questions about chronic diseases (i.e. hypertension, ischemic heart disease, diabetes, frequent headaches, insomnia and backache) were included in health-related part.

\section{Warr-Cook-Wall (WCW) Job Satisfaction Questionnaire}

Job satisfaction was measured with the Warr-Cook-Wall (WCW) job satisfaction scale developed by Warr et al. [16] It included 15 questions with seven possible responses (extremely dissatisfied $=1$, very dissatisfied $=2$, moderately dissatisfied $=3$, not sure $=4$, moderately satisfied $=5$, very satisfied $=6$ and extremely satisfied $=7$ ). The responses were coded using seven (7) points Likert scale $(1=$ extreme dissatisfaction to $7=$ extreme satisfaction $)$. The score range was 15 to 105. Response 4 and above considered as a degree of satisfaction. A higher overall mean score indicates higher job satisfaction. The WCW scale included: how satisfied physicians with the following: Physical work conditions, freedom of working method, colleagues and fellow workers, recognition of work, immediate boss, amount of responsibility, monthly income, opportunity to use abilities, relations between management and workers in the organization, chance of promotion, organization's management, attention given to your suggestions, working hours, the amount of variety in job and finally job security.

\section{General Health Questionnaire (GHQ-12, Mental Health)}

The General Health Questionnaire-12 was used to measure the mental health of 
physicians. The GHQ scale consisted of six positive and six negative items, concerning the past few weeks. "Have you recently been able to enjoy your normal day to day activities?" is an example of a positive item, while "Have you recently been thinking of yourself as a worthless person?" is an example of a negative item. The responses to the positive items were "Better than usual" $=0$, "Same as usual" $=1$, "Less than usual" $=2$ and "Much less than usual" $=3$. The responses to the negative items are "Not at all" $=0$, "No more than usual" = 1, "Rather more than usual" $=2$ and "Much more than usual" $=3$. Responses were coded using an un-weighted four-point Likert scale $(0,1,2$, and 3$)$. The GHQ has excellent psychometric properties as a screening instrument for psychiatric disorders. The analysis of psychological morbidity will be based on the number of respondents scoring $<4$ or more (out of a possible 12). GHQ scores were divided into normal (0 - 3) and high ( $\geq 4)$ as recommended in the GHQ manual [17].

\section{Data Collection}

We received 417 filled questionnaires, and 31 no consent forms, which represented survey response of $55.9 \%$ and no consent rate of $4.2 \%$. The level of significance was set at $\alpha<0.05$ (two-tailed). A p-value of $\leq 0.05$ was considered statistically significant. Data analyses were done using the Statistical Package for Social Sciences, (IBM SPSS Statistics 24, IBM Corporation, Armonk, NY, USA 2015).

Qualitative variables were summarized by frequency and percentage, while the normally distributed quantitative variables were described by the mean and standard deviation and the non-normally distributed variables were described by the median and inter-quartile range. Pearson's Chi-square test was used to assess the association between two qualitative variables. T-test was used to compare between means of two independent normally distributed groups, while Mann-Whitney $U$ test was used for comparing the median between groups with non-normal frequency distribution variables.

\section{Results}

Generally, the primary health care (PHC) physicians were more satisfied as compared to the previous studies done in Kuwait and the surrounding region. They were moderately satisfied with most of the factors like work surroundings, freedom of working method, recognition of work, the amount of responsibility given, income, opportunity to use their abilities, chances of promotion, attention given to their suggestions, relationship with hospital doctors, relationship with colleagues and fellow workers, relations between management and workers in the work set up, the working hours and finally the amount of variety in their job. The physicians were not satisfied with one factor, that was their job security especially the male physicians working in the primary health care centers in $\mathrm{Ku}$ wait. The physicians working in the primary health care centers were very satisfied with their immediate supervisor, as revealed in the data analysis. Farwaniya 
region PHC physicians had the highest satisfaction score (Mean, SD $72.7 \pm 13.1$ ) compared to the least in Ahmadi region (Mean, SD $66.4 \pm 13.9$ ). There was an overall improvement in satisfaction score as compared to the previous studies done in the same region.

Table 1 shows the frequency distribution with the actual percentages of all the socio-demographic variables. Male to female ratio of the primary health care (PHC) physicians were $40 \%$ and $60 \%$ respectively. The median age of PHC physicians was 40 years; about $58 \%$ of physicians were in the age range of $30-50$ years. Kuwaiti physicians comprised about $25 \%$ of the total primary health care physicians working in PHC clinics. Very few PHC physicians were single (8.4\%), rather most of them (about 87\%) were married. Regarding the monthly income, about $50 \%$ of physicians were in the category of less than KD 1500 only. About $30 \%$ of the PHC physicians hold the basic medical degree (MBBS), while $45 \%$ of

Table 1. Socio-demographic characteristics and its association with nationality among primary health care physicians working in primary health care centers in Kuwait $(n=417)$.

\begin{tabular}{|c|c|c|c|c|}
\hline \multirow[b]{2}{*}{ Characteristics } & \multirow[b]{2}{*}{ Frequency n (\%) } & \multicolumn{2}{|c|}{ Nationality } & \multirow[b]{2}{*}{ p-value } \\
\hline & & $\begin{array}{l}\text { Kuwaiti } \\
(\mathrm{n}=104)\end{array}$ & $\begin{array}{l}\text { Non-Kuwaiti } \\
\quad(n=307)\end{array}$ & \\
\hline Gender & & & & 0.004 \\
\hline Male & $170(40.8)$ & $30(28.8)$ & $138(45.0)$ & \\
\hline Female & $247(59.2)$ & $74(71.2)$ & $169(55.0)$ & \\
\hline Age, Years & & & & $<0.001$ \\
\hline$<30$ & $31(7.4)$ & $21(20.8)$ & $10(3.5)$ & \\
\hline $30-39$ & $152(36.5)$ & $48(47.5)$ & $102(35.7)$ & \\
\hline $40-49$ & $92(22.1)$ & $17(16.8)$ & $73(25.5)$ & \\
\hline$\geq 50$ & $118(28.3)$ & $15(14.9)$ & $101(35.3)$ & \\
\hline Median, IQR & $40(34-51)$ & & & \\
\hline \multicolumn{5}{|l|}{ Nationality } \\
\hline Kuwaiti & $104(24.9)$ & & & \\
\hline Non-Kuwaiti & $307(73.6)$ & & & \\
\hline Marital Status & & & & $<0.001$ \\
\hline Single & $35(8.4)$ & $19(18.4)$ & $15(4.9)$ & \\
\hline Married & $364(87.3)$ & $77(74.8)$ & $282(91.9)$ & \\
\hline Divorced/Widowed & $17(4.1)$ & $7(6.8)$ & $10(3.3)$ & \\
\hline Monthly Income (KD) & & & & $<0.001$ \\
\hline $1000-<1500$ & $196(47.0)$ & $2(1.9)$ & $189(62.8)$ & \\
\hline $1500-<2000$ & $128(30.7)$ & $28(27.2)$ & 99 (32.9) & \\
\hline$\geq 2000$ & $86(20.6)$ & $73(70.9)$ & $13(4.3)$ & \\
\hline Highest Degree & & & & $<0.001$ \\
\hline M.B.B.S. & $123(29.5)$ & $26(26.5)$ & $95(32.0)$ & \\
\hline
\end{tabular}




\section{Continued}

\begin{tabular}{|c|c|c|c|c|}
\hline MSc/Diploma & $186(44.6)$ & $8(8.2)$ & $174(58.6)$ & \\
\hline Fellowship/Membership & $69(16.5)$ & $59(60.2)$ & $10(3.4)$ & \\
\hline Others & $23(5.5)$ & $5(5.1)$ & $18(6.1)$ & \\
\hline Rank & & & & $<0.001$ \\
\hline Assistant Registrar & $123(29.5)$ & $25(24.5)$ & $96(33.8)$ & \\
\hline Registrar & $119(28.5)$ & $15(14.7)$ & $101(35.6)$ & \\
\hline Senior Registrar & $96(23.0)$ & $25(24.5)$ & $71(25.0)$ & \\
\hline Specialist & $53(12.7)$ & $33(36.3)$ & $16(5.6)$ & \\
\hline Living with Spouse & & & & 0.034 \\
\hline Yes & $372(89.2)$ & $98(97.0)$ & $270(90.0)$ & \\
\hline No & $34(8.2)$ & $3(3.0)$ & $30(10.0)$ & \\
\hline Children & & & & $<0.001$ \\
\hline None & $59(14.1)$ & $30(29.4)$ & $26(8.5)$ & \\
\hline $1-2$ & $137(32.9)$ & $28(27.5)$ & $109(35.7)$ & \\
\hline $3-4$ & $183(43.9)$ & $29(28.4)$ & $152(49.8)$ & \\
\hline$\geq 5$ & $34(8.2)$ & $15(14.7)$ & $18(5.9)$ & \\
\hline Area of Residence & & & & $<0.001$ \\
\hline Capital & $52(12.5)$ & $40(38.5)$ & $11(3.6)$ & \\
\hline Hawally & $170(40.8)$ & $34(32.7)$ & $132(43.3)$ & \\
\hline Farwaniya & $83(19.9)$ & $9(8.7)$ & $74(24.3)$ & \\
\hline Ahmadi/Mubarak & $84(20.1)$ & $19(18.3)$ & $64(21.0)$ & \\
\hline Jahra & $26(6.2)$ & $2(1.9)$ & $24(7.9)$ & \\
\hline Area of Job & & & & $<0.001$ \\
\hline Capital & $86(20.6)$ & $54(51.9)$ & $32(10.5)$ & \\
\hline Hawally & $69(16.5)$ & $13(12.5)$ & $52(17.0)$ & \\
\hline Farwaniya & $107(25.7)$ & $18(17.3)$ & $89(29.1)$ & \\
\hline Ahmadi/Mubarak & $94(22.5)$ & $17(16.3)$ & $75(24.5)$ & \\
\hline Jahra & $60(14.4)$ & $2(1.9)$ & $58(19.0)$ & \\
\hline Smoking Status & & & & 0.203 \\
\hline Never Smoker & $358(85.9)$ & $95(91.3)$ & $258(84.6)$ & \\
\hline Ex-Smoker & $33(7.9)$ & $6(5.8)$ & $27(8.9)$ & \\
\hline Current Smoker & $24(5.8)$ & $3(2.9)$ & $20(6.6)$ & \\
\hline BMI $\left(\mathrm{kg} / \mathrm{m}^{2}\right)$ & & & & $<0.001$ \\
\hline Normal $(<25)$ & $94(22.5)$ & $42(41.6)$ & $50(17.6)$ & \\
\hline Overweight (25 - 29) & $171(41.0)$ & $36(35.6)$ & $132(46.5)$ & \\
\hline Obese $(\geq 30)$ & $125(30.0)$ & $23(22.8)$ & $102(35.9)$ & \\
\hline Median, IQR & $27.8(25.1-30.8)$ & & & \\
\hline
\end{tabular}

$\%=$ Column \%; BMI = Body mass index; p-values were generated using Pearson Chi-square test; Frequencies may not add to the total number of participants (417) due to some missing values. 
the PHC physicians were having higher (Master/Postgraduate diploma) qualifications, and about $18 \%$ - 20\% of PHC physicians had fellowship/membership. About $60 \%$ of primary health care physicians were at the level of assistant registrar and registrar (each around 30\%). There were about 23\% of senior registrars and $13 \%$ specialists. Most of the primary health care physicians were living with their families. About $15 \%$ of primary health care physicians had no children and almost $45 \%$ had 3 - 4 children. Most of the primary health care physicians (about 40\%) were living in Hawally governorate followed by Farwaniya and Ahmadi (each around 20\%). Regarding the job area, most of the primary health care physicians (about 25\%) were from Farwaniya region followed by Capital and Ahmadi governorate (about $20 \%$ and $22 \%$ respectively). Almost $85 \%$ of primary health care physicians were never smoker (over reporting could be considered). About $70 \%$ of primary health care physicians were overweight and obese having BMI > $25 \mathrm{~kg} / \mathrm{m}^{2}$. The median BMI of primary health care physicians was $27.8 \mathrm{~kg} / \mathrm{m}^{2}$.

It also shows the association between nationality (Kuwaiti versus non-Kuwaiti) and socio-demographic characteristics of PHC (primary health care) physicians working in PHC clinics. Age, marital status, monthly income, highest earned degree, job rank, number of children, area of residence, area of job and BMI were highly significant $(\mathrm{p}<0.001)$, while gender and living with spouse had $\mathrm{p}$-value $<0.01$ and 0.05 respectively. Smoking status was not significant $(\mathrm{p}>$ $0.05)$, as the over-reported of never smoker and lower reporting of current smoker status could be considered.

Table 2 shows the association between job satisfaction score with sociodemographic characteristics of PHC physicians working in PHC clinics. Warr-Cook-Wall job satisfaction questionnaire was used to assess the job satisfaction score. Job satisfaction score ranged from 15 - 105. Job satisfaction score tertiles were used to have three categories (low $\leq 67$, medium $68-78$ and high $\geq$ 79). The job rank and area of job showed significant association $(\mathrm{p}<0.01$ and $0.05)$ respectively. Specialists, senior registrar and assistant registrars showed highly significant association with high satisfaction score. Physicians working in Farwaniya (42\%), Hawally (38\%) and Capital (36\%) governorates had high significant association with high job satisfaction score. As far as family history is concerned, physicians living with their spouses were more satisfied than others and similarly those having no children yet, were highly satisfied than the rest of their counterparts.

Table 3 shows the association of mental health score (GHQ-12) with sociodemographic characteristics among PHC physicians working in PHC clinics. Age $(\mathrm{p}<0.05)$, job rank $(\mathrm{p}<0.01)$ and the number of children show the significant $\mathrm{p}$-value $<0.05$. Age group $30-39$ and $40-49$ years showed more distress (GHQ score $\geq 4$ ). Married physicians had more mental distress than the non-married, as they might be worried about their spouses because of long working hours and on-call night duties. Physicians having no children yet had the least mental distress, possibly because of no worries about children. Job rank of assistant registrar and registrar (junior rank positions) showed more distress. 
Table 2. Association of job satisfaction score with socio-demographic characteristics among primary health care physicians working in primary health care clinics in Kuwait $(\mathrm{n}=417)$.

\begin{tabular}{|c|c|c|c|c|}
\hline \multirow[b]{2}{*}{ Variable } & \multicolumn{3}{|c|}{ Job Satisfaction Score $\mathrm{e}^{\mathrm{a}}$} & \multirow[b]{2}{*}{$\mathrm{p}$-value ${ }^{\mathrm{b}}$} \\
\hline & $\begin{array}{c}\text { Low } \\
(\leq 67), \mathrm{n}(\%)\end{array}$ & $\begin{array}{c}\text { Medium } \\
(68-78), \mathrm{n}(\%)\end{array}$ & $\begin{array}{c}\text { High } \\
(\geq 79), \text { n (\%) }\end{array}$ & \\
\hline Age, Years & & & & 0.16 \\
\hline$<30$ & $7(22.6)$ & $12(38.7)$ & $12(38.7)$ & \\
\hline $30-39$ & $50(33.3)$ & $45(30.0)$ & $55(36.7)$ & \\
\hline $40-49$ & $36(39.6)$ & $32(35.2)$ & $23(25.3)$ & \\
\hline$\geq 50$ & $28(24.1)$ & $44(37.9)$ & $44(37.9)$ & \\
\hline Gender & & & & 0.48 \\
\hline Male & $54(32.3)$ & $62(37.1)$ & $51(30.5)$ & \\
\hline Female & $77(31.4)$ & $80(32.7)$ & $88(35.9)$ & \\
\hline Nationality & & & & 0.54 \\
\hline Kuwaiti & $36(34.6)$ & $31(29.8)$ & $37(35.6)$ & \\
\hline Non-Kuwaiti & $95(31.5)$ & $108(35.8)$ & $99(32.8)$ & \\
\hline Marital Status & & & & 0.07 \\
\hline Single & $9(25.7)$ & $11(31.4)$ & $15(42.9)$ & \\
\hline Married & $118(32.9)$ & $120(33.4)$ & $121(33.7)$ & \\
\hline Divorced/Widowed & $3(17.6)$ & $11(64.7)$ & $3(17.6)$ & \\
\hline Monthly Income, KD & & & & 0.21 \\
\hline$<1500$ & $65(33.7)$ & $68(35.2)$ & $60(31.1)$ & \\
\hline $1500-<2500$ & $32(25.4)$ & $51(40.5)$ & $43(34.1)$ & \\
\hline$\geq 3000$ & $30(34.9)$ & $23(26.7)$ & $33(38.4)$ & \\
\hline Highest Degree & & & & 0.36 \\
\hline M.B.B.S. & $40(32.8)$ & $43(35.2)$ & $39(32.0)$ & \\
\hline MSc/Diploma & $53(29.0)$ & $68(37.2)$ & $62(33.9)$ & \\
\hline Fellowship/Membership & $24(34.8)$ & $17(24.6)$ & $28(40.6)$ & \\
\hline Others & $9(40.9)$ & $9(40.9)$ & $4(18.2)$ & \\
\hline Rank & & & & 0.008 \\
\hline Assistant Registrar & $37(30.3)$ & $39(32.0)$ & $46(37.7)$ & \\
\hline Registrar & $46(39.3)$ & 49 (41.9) & $22(18.8)$ & \\
\hline
\end{tabular}




\section{Continued}

\begin{tabular}{|c|c|c|c|c|}
\hline Senior Registrar & $27(28.4)$ & $29(30.5)$ & $39(41.1)$ & \\
\hline Specialist & $13(25.0)$ & $16(30.8)$ & $23(44.2)$ & \\
\hline Living with Spouse & & & & 0.49 \\
\hline Yes & $120(32.7)$ & $122(33.2)$ & $125(34.1)$ & \\
\hline No & $8(23.5)$ & $14(41.2)$ & $12(35.3)$ & \\
\hline Children & & & & 0.49 \\
\hline None & $16(27.1)$ & $20(33.9)$ & $23(39.0)$ & \\
\hline $1-2$ & $47(34.6)$ & $40(29.40$ & $49(36.0)$ & \\
\hline $3-4$ & $60(33.3)$ & $66(36.7)$ & $54(30.0)$ & \\
\hline$\geq 5$ & $7(21.2)$ & $14(42.4)$ & $12(36.4)$ & \\
\hline Smoking Status & & & & 0.35 \\
\hline Never Smoked & $107(30.1)$ & $122(34.4)$ & $126(35.5)$ & \\
\hline Ex-Smoker & $12(37.5)$ & $14(43.8)$ & $6(18.8)$ & \\
\hline Current Smoker & $12(50.0)$ & $6(25.0)$ & $6(25.0)$ & \\
\hline BMI $\left(\mathrm{kg} / \mathrm{m}^{2}\right)$ & & & & 0.51 \\
\hline Normal $(<25)$ & $26(28.0)$ & $31(33.3)$ & $36(38.7)$ & \\
\hline Overweight (25 - 29) & $50(29.8)$ & $64(38.1)$ & $54(32.1)$ & \\
\hline Obese $(\geq 30)$ & $45(36.3)$ & $40(32.3)$ & $39(31.5)$ & \\
\hline Area of Residence & & & & 0.703 \\
\hline Capital & $14(26.9)$ & $18(34.6)$ & $20(38.5)$ & \\
\hline Hawally & $54(32.0)$ & $53(31.4)$ & $62(36.7)$ & \\
\hline Farwaniya & $24(30.0)$ & $28(35.0)$ & $28(35.0)$ & \\
\hline Ahmadi/Mubarak & $31(37.3)$ & $30(36.1)$ & $22(26.5)$ & \\
\hline Jahra & $7(26.9)$ & $12(46.2)$ & $7(26.9)$ & \\
\hline Area of Job & & & & 0.050 \\
\hline Capital & $29(34.5)$ & $25(29.8)$ & $30(35.7)$ & \\
\hline Hawally & $21(30.4)$ & $22(31.9)$ & $26(37.7)$ & \\
\hline Farwaniya & $22(20.8)$ & $40(37.7)$ & $44(41.5)$ & \\
\hline Ahmadi/Mubarak & 39 (41.9) & $31(33.3)$ & $23(24.7)$ & \\
\hline Jahra & $20(33.9)$ & $24(40.7)$ & $15(25.4)$ & \\
\hline
\end{tabular}

${ }^{\mathrm{a} J o b}$ satisfaction tertiles; $\mathrm{p}^{\mathrm{b}}, \mathrm{p}$-values were generated using Pearson Chi-square test. 
Table 3. Association of mental health score with socio-demographic characteristics, among primary health care physicians, working in primary health care clinics in Kuwait $(\mathrm{n}=417)$.

\begin{tabular}{|c|c|c|c|}
\hline \multirow{2}{*}{ Characteristics } & \multicolumn{2}{|c|}{ Mental Health Score (GHQ-12) } & \multirow{2}{*}{ p-value } \\
\hline & $<4, \mathrm{n}(\%)$ & $\geq 4, \mathrm{n}(\%)$ & \\
\hline Age, Years & & & 0.015 \\
\hline$<30$ & $22(71.0)$ & $9(29.0)$ & \\
\hline $30-39$ & $81(54.0)$ & $69(46.0)$ & \\
\hline $40-49$ & $53(58.2)$ & $38(41.8)$ & \\
\hline$\geq 50$ & $84(71.8)$ & $33(28.2)$ & \\
\hline Gender & & & 1.00 \\
\hline Male & $104(61.9)$ & $64(38.1)$ & \\
\hline Female & $151(61.6)$ & $94(38.4)$ & \\
\hline Nationality & & & 0.56 \\
\hline Kuwaiti & $61(58.7)$ & $43(41.3)$ & \\
\hline Non-Kuwaiti & $188(62.0)$ & $115(38.0)$ & \\
\hline Marital Status & & & 0.17 \\
\hline Single & $25(71.4)$ & $10(28.6)$ & \\
\hline Married & $217(60.3)$ & $143(39.7)$ & \\
\hline Divorced/Widowed & $4(50.0)$ & $4(50.0)$ & \\
\hline Monthly Income (KD) & & & 0.384 \\
\hline $1000-<1500$ & $113(58.5)$ & $80(41.5)$ & \\
\hline $1500-<2000$ & $84(66.1)$ & $43(33.9)$ & \\
\hline$\geq 2000$ & $54(62.8)$ & $32(37.2)$ & \\
\hline Highest Degree & & & 0.778 \\
\hline M.B.B.S. & $75(61.5)$ & $47(38.5)$ & \\
\hline MSc/Diploma & $117(63.6)$ & $67(36.4)$ & \\
\hline Fellowship/Membership & $39(56.5)$ & $30(43.5)$ & \\
\hline Others & $14(63.6)$ & $8(36.4)$ & \\
\hline Rank & & & 0.002 \\
\hline Assistant Registrar & $73(59.8)$ & $49(40.2)$ & \\
\hline Registrar & $58(49.6)$ & $59(50.4)$ & \\
\hline Senior Registrar & $65(67.7)$ & $31(32.3)$ & \\
\hline Specialist & $38(73.1)$ & $14(26.9)$ & \\
\hline Living with Spouse & & & 0.196 \\
\hline Yes & $223(60.6)$ & $145(39.4)$ & \\
\hline No & $25(73.5)$ & $9(26.5)$ & \\
\hline Children & & & 0.021 \\
\hline None & $42(71.2)$ & $17(28.8)$ & \\
\hline $1-2$ & $91(66.9)$ & $45(33.1)$ & \\
\hline $3-4$ & $97(53.6)$ & $84(46.4)$ & \\
\hline$\geq 5$ & $23(69.7)$ & $10(30.3)$ & \\
\hline
\end{tabular}




\section{Continued}

\begin{tabular}{|c|c|c|c|}
\hline Area of Residence & & & 0.216 \\
\hline Capital & $39(75.0)$ & $13(25.0)$ & \\
\hline Hawally & $105(61.8)$ & $65(38.2)$ & \\
\hline Farwaniya & $49(61.3)$ & $31(38.8)$ & \\
\hline Ahmadi/Mubarak & $46(54.8)$ & $38(45.2)$ & \\
\hline Jahra & $15(57.7)$ & $11(42.3)$ & \\
\hline Area of Job & & & 0.801 \\
\hline Capital & $52(60.5)$ & $34(39.5)$ & \\
\hline Hawally & $46(66.7)$ & $23(33.3)$ & \\
\hline Farwaniya & $66(63.5)$ & $38(36.5)$ & \\
\hline Ahmadi/Mubarak & $54(57.4)$ & $40(42.6)$ & \\
\hline Jahra & $36(61.0)$ & $23(39.0)$ & \\
\hline Smoking Status & & & 0.411 \\
\hline Never Smoker & $223(62.8)$ & $132(37.2)$ & \\
\hline Ex-Smoker & $18(54.5)$ & $15(45.5)$ & \\
\hline Current Smoker & $12(52.2)$ & $11(47.8)$ & \\
\hline BMI $\left(\mathrm{kg} / \mathrm{m}^{2}\right)$ & & & 0.867 \\
\hline Normal $(<25)$ & $60(63.8)$ & $34(36.2)$ & \\
\hline Overweight (25 - 29.9) & $101(60.5)$ & $66(39.5)$ & \\
\hline Obese $(\geq 30)$ & $77(61.6)$ & $48(38.4)$ & \\
\hline
\end{tabular}

$\%=$ Row \%; BMI = Body mass index; p-values were generated using Pearson Chi-square test; Frequencies may not add to the total number of participants (417) due to some missing values.

Table 4 shows the association of job satisfaction score tertiles with chronic diseases and with work related aspects among PHC physicians working in PHC clinics. p-values were generated using Pearson Chi-square test. In the first part of Table 4, insomnia, diabetes and backache had a significant association with p-value $<0.01,0.05$ and 0.05 respectively. Insomnia was prevalent (50\%) in those with low satisfaction score. Similarly, diabetes (about 48\%) and backache (about 35\%) were more prevalent among those physicians with low job satisfaction score. The second part of this table shows the association of work-related aspects with job satisfaction. It was obvious that physicians having experience less than five years and more than fifteen years were less satisfied than the rest of their colleagues. Similarly, physicians having working hours less than six hours were more satisfied than the rest of their group. Physicians having more than 3 on-call night duties per month were most dissatisfied. Similarly, physicians examining more than 75 patients per shift in a day were least satisfied. It was very clear from the results that physicians had high satisfaction with less working hours, less on-call duties and a low number of patients examined during their practice.

Table 5 shows the association of job satisfaction score with mental health 
among PHC physicians working in PHC clinics. There is strong association between mental health and job satisfaction score ( $\mathrm{p}$-value $<0.001$ ). As with low job satisfaction score, PHC physicians had more mental distress.

Figure 1 shows the association of job satisfaction score with mental health among PHC physicians working in PHC clinics. There is strong association between mental health and job satisfaction score ( $\mathrm{p}$-value $<0.001$ ). As with low job satisfaction score, PHC physicians had more mental distress $(\mathrm{p}<0.001)$.

Table 4. Association of job satisfaction score with chronic diseases and work-related aspects among primary health care physicians working in primary health care clinics in Kuwait $(\mathrm{n}=417)$.

\begin{tabular}{|c|c|c|c|c|}
\hline \multirow[b]{2}{*}{ Variable } & \multicolumn{3}{|c|}{ Job Satisfaction Score } & \multirow[b]{2}{*}{ p-value } \\
\hline & $\begin{array}{c}\text { Low } \\
(\leq 67), \mathrm{n}(\%)\end{array}$ & $\begin{array}{c}\text { Medium } \\
(68-78), \mathrm{n}(\%)\end{array}$ & $\begin{array}{c}\text { High } \\
(\geq 79), \text { n (\%) }\end{array}$ & \\
\hline Hypertension & & & & 0.823 \\
\hline Yes & $31(32.3)$ & $35(36.5)$ & $30(31.3)$ & \\
\hline No & $89(30.9)$ & $99(34.4)$ & $100(34.7)$ & \\
\hline Ischemic Heart Disease & & & & 0.443 \\
\hline Yes & $4(28.6)$ & $7(50.0)$ & $3(21.4)$ & \\
\hline No & $107(30.4)$ & $122(34.7)$ & $123(34.9)$ & \\
\hline Diabetes & & & & 0.020 \\
\hline Yes & $23(47.9)$ & $14(29.2)$ & $11(22.9)$ & \\
\hline No & $91(28.3)$ & $115(35.7)$ & $116(36.0)$ & \\
\hline Frequent Headache & & & & 0.345 \\
\hline Yes & $52(36.4)$ & $47(32.9)$ & $44(30.8)$ & \\
\hline No & $71(29.3)$ & $85(35.1)$ & $86(35.5)$ & \\
\hline Insomnia & & & & $<0.001$ \\
\hline Yes & $38(50.0)$ & $23(30.3)$ & $15(19.7)$ & \\
\hline No & $81(27.4)$ & $105(35.5)$ & $110(37.2)$ & \\
\hline Backache & & & & 0.050 \\
\hline Yes & $72(34.8)$ & $76(36.7)$ & $59(28.5)$ & \\
\hline No & $49(27.2)$ & $59(32.8)$ & $72(40.0)$ & \\
\hline Number of Working Years & & & & 0.77 \\
\hline$\leq 5$ & $51(32.3)$ & $55(34.8)$ & $52(32.9)$ & \\
\hline$>5-15$ & $46(34.1)$ & $42(31.1)$ & $47(34.8)$ & \\
\hline$>15$ & $33(28.4)$ & $45(38.8)$ & $38(32.8)$ & \\
\hline $\begin{array}{c}\text { Number of Working } \\
\text { Hours Per Day }\end{array}$ & & & & 0.25 \\
\hline$\leq 6$ & $29(32.6)$ & $26(29.2)$ & $34(38.2)$ & \\
\hline 7 & $63(28.3)$ & $83(37.2)$ & $77(34.5)$ & \\
\hline$\geq 8$ & $39(39.0)$ & $33(33.0)$ & $28(28.0)$ & \\
\hline
\end{tabular}




\section{Continued}

\begin{tabular}{ccccc}
\hline $\begin{array}{c}\text { Number of On-Calls/Month } \\
\text { None }\end{array}$ & $45(30.0)$ & $52(34.7)$ & $53(35.3)$ & 0.07 \\
$1-2$ & $17(21.5)$ & $29(36.7)$ & $33(41.8)$ & \\
$\geq 3$ & $44(41.1)$ & $29(27.1)$ & $34(31.8)$ & \\
\hline Number of Patients Per Day & & & $49(37.1)$ & \\
$<50$ & $40(30.3)$ & $43(32.6)$ & $43(33.9)$ & \\
$50-<75$ & $40(31.5)$ & $44(34.6)$ & $44(30.3)$ & \\
$\geq 75$ & $49(33.8)$ & $52(39.5)$ & & \\
\hline
\end{tabular}

p-values were generated using Pearson Chi-square test; $\%=$ Row $\%$.

Table 5. Association of job satisfaction score with mental health score among primary health care physicians working in primary health care clinics in Kuwait $(\mathrm{n}=417)$.

\begin{tabular}{|c|c|c|c|}
\hline \multirow{2}{*}{ Variable } & \multicolumn{2}{|c|}{ Mental Health Score (GHQ-12) } & \multirow{2}{*}{ p-value } \\
\hline & $<4, \mathrm{n}(\%)$ & $\geq 4, \mathrm{n}(\%)$ & \\
\hline Job Satisfaction Score & & & $<0.001$ \\
\hline Low $(\leq 67)$ & $40(30.5)$ & $91(69.5)$ & \\
\hline Medium (68 - 78) & $90(64.3)$ & $50(35.7)$ & \\
\hline High $(\geq 79)$ & $122(87.8)$ & $17(12.2)$ & \\
\hline
\end{tabular}

p-values were generated using Pearson Chi-square; \% = Row $\%$.

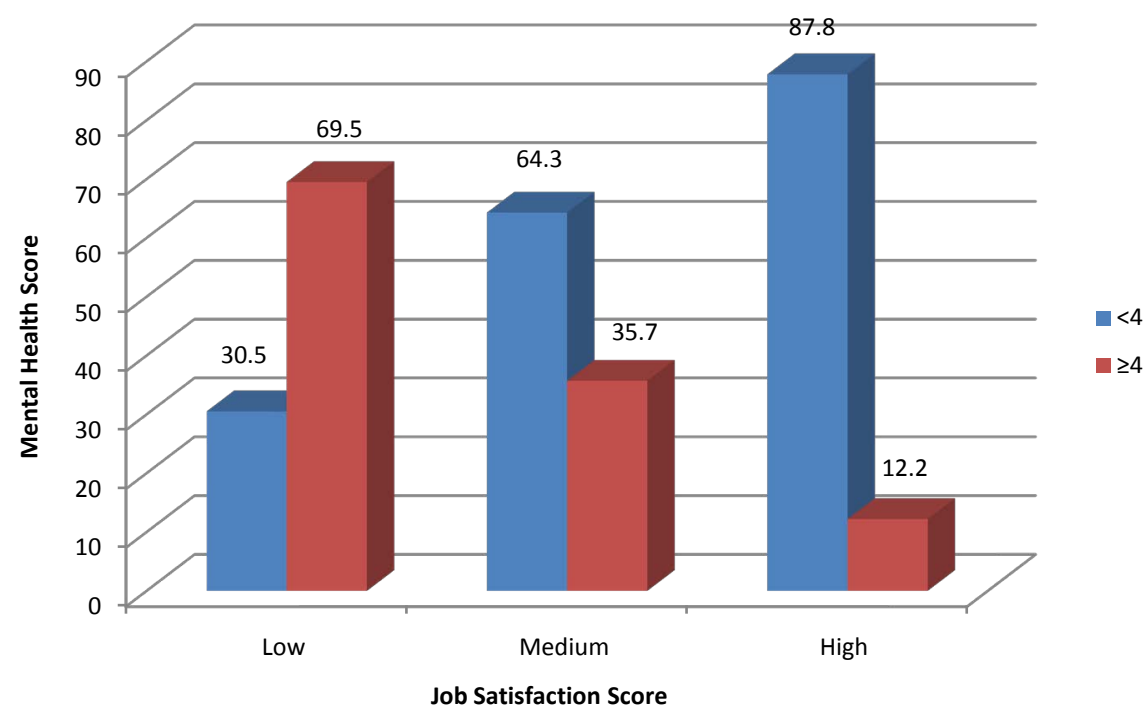

Figure 1. Association of job satisfaction score with mental health score among primary health care physicians working in primary health care clinics in Kuwait (p-value $<0.001$ ).

\section{Discussions}

There is a consensus that job satisfaction may be defined as the degree of positive affect towards a job or its components. This is determined by characteristics both of the individual and of the job, and particularly how work is recognized 
within the corporate work environment. Many studies had shown that older physicians were more satisfied than younger physicians. We found factors significantly associated with satisfaction to include both physician's rank (job title) and job's area. Our study showed an increase in job satisfaction compared to past experiences in primary health care centers in Kuwait. It might be due to the increase in salaries, the increase in the number of doctors and other facilities in primary health care centres. Insomnia was prevalent (50\%) in those with low satisfaction score. Similarly, diabetes (about 48\%) and backache (about 35\%) were more prevalent among those physicians with low job satisfaction score. Age group 30 - 39 and 40 - 49 years showed more distress (GHQ score $>12$ ). Similarly job rank of assistant registrar and registrar showed more distress and so is the case with more number of children. There is a significant association of mental health with the number of working years in PHC clinics since joining. Insomnia and backache had significant association (p-value $<0.05$ ). As with low job satisfaction score, PHC physicians had more mental distress $(\mathrm{p}<0.001)$.

A study of US physicians showed that physicians in 1997 were less satisfied in every aspect of their professional life than those asked similar questions in 1986. The respondents in the US study were dissatisfied with the time they devoted to their patients and the lack of incentives for high quality care [18]. Another study showed that being appreciated for high performance was most important to job satisfaction of non-physician staff. This is important because recognition of performance facilitates teamwork. Work satisfaction of primary care teams correlates positively with higher scores of outcome quality measures [19].

In England, for both males and females, the overall job satisfaction declined from 1987 to 1990 and then improved from 1990 to 1998, although the reported level of stress in relation to many aspects of work has continued to increase. The workload was increasing, particularly in relation to administration. GPs were, furthermore suspicious of the motivation for change, believing that financial restrain, rather than health improvement, was the goal [20].

Another survey that was conducted in Scotland in 2001 showed that most of job stress was increasing workloads, paperwork, and insufficient time to do justice to the job as well as increased and inappropriate demands from patients. While female, young (under 40 years) and old (55 years and over) general practitioners (GPs) non-principals and PMS (Personal Medical Services) GPs who work less than 50 hours per week were more likely to be satisfied with their job and reported lower level of stress [21]. One study in Australia compared the job satisfaction of physician and non-physician staff and showed that there is overall satisfaction with colleagues but dissatisfaction with income in both groups of employees [22].

A study done in Barcelona showed that there was a positive association between overall satisfaction and the fewer years working in primary health [23]. Our data showed a significant association between physician's working years and gender. This was consistent with other studies done in other countries, 
which show that older doctors are more generally satisfied with their jobs than younger doctors. It is possible that young physicians have greater demands and, as age advances, the possibility to adapt increases. A study reported that those who are dissatisfied with their work were most likely to leave the practice [24]. In contrast to other studies that showed that family medicine specialists reported lower satisfaction. Our study showed that there was no significant difference between being a specialist in family medicine and overall satisfaction. This can be attributed to the similarity of working conditions for all primary care physicians. Similar to our findings, a study showed that there was no significant satisfaction difference between genders. Aspects such as physician's health and the number of sick leave days have no relation to job satisfaction [25]. There is a commonly held belief that doctors are indispensable and should carry on working even when they are ill. The physicians who face fewer problems with patients are usually more satisfied. One of the female physician from our study respondent reported that she often had a feeling of being guilty, eventually resulting in dissatisfaction about the misuse of laboratory investigations (especially biochemistry/hormones), over demanded by the patients, who actually did not need to be investigated at the point.

This can be explained by the study, reported that all physicians included mentioned that changes in physician-patient relationships are one of the most important factors that have impact on their satisfaction [26]. A study of 89 GPs working at Capital Health Region, in Kuwait (2005) showed that the overall physician's satisfaction was similar to a study done in Kuwait in 1998 revealing that the level of overall satisfaction was $66.9 \%$ [27]. This meant that there was no improvement in different items of job satisfaction during this period. Comparing with our study, the satisfaction score has improved to $69.9 \%$ for the same governorate (Capital Health Region) study done in 2005, as mentioned above.

Language barrier is also a source of less satisfaction, but the employees who had a Kuwaiti supervisor showed more satisfaction, probably he/she can easily provide more support in getting things done. There is an overall improvement in satisfaction score among primary health care physicians working in primary health care centers in Kuwait as compared to the previous studies done in the same region.

\section{Conclusions}

In summary, there is an association of job satisfaction with physician's health and wellness. Low job satisfaction is associated with poor mental and physical health and could have a potential impact on sickness absence. Theoretically, dissatisfaction is thought of as a short term outcome of stress, while mental health is a result of chronic stress and dissatisfaction. By measuring the magnitude of job satisfaction among the primary health care physicians and assessing its effect on their mental health, health authorities and public health specialists can develop methods to control and improve the conditions causing dissatisfaction and 
in turn improve physician's health. Such improvements will lead to higher physicians' productivity and better healthcare services. Our findings have some implications. Firstly, physicians should have better access to their superiors and colleagues in the clinics. They should be recognized for professionalism and competence by means of regular scientific meetings and improved feedback system. Secondly, there is an urgent need to improve the work conditions and to provide competitive services by elevating the standards for recruiting the assisting staff in primary care clinics. Finally, a revised policy of promotion for physicians needs to be worked out to keep the general practice an attractive place, especially for young expatriate physicians.

\section{Conflicts of Interest}

The authors declare no conflicts of interest regarding the publication of this paper.

\section{References}

[1] World Health Organization (1978) The Declaration of Alma-Ata. WHO, Geneva.

[2] Wallace, J.E., Lemaire, J.B. and Ghali, W.A. (2009) Physician Wellness: A Missing Quality Indicator. The Lancet, 374, 1714-1721. https://doi.org/10.1016/S0140-6736(09)61424-0

[3] Koch, K., Miksch, A., Schurmann, C., Joos, S. and Sawicki, P.T. (2011) The German Health Care System in International Comparison: The Primary Care Physician's Perspective. Deutsches Ärzteblatt International, 108, 255-261. https://doi.org/10.3238/arztebl.2011.0255

[4] Linzer, M., Manwell, L.B., Williams, E.S., et al. (2009) Working Conditions in Primary Care: Physician Reactions and Care Quality. Annals of Internal Medicine, 151, 28-36. https://doi.org/10.7326/0003-4819-151-1-200907070-00006

[5] DeVoe, J., Fryer Jr., G.E., Straub, A., McCann, J. and Fairbrother, G. (2007) Congruent Satisfaction: Is There Geographic Correlation between Patient and Physician Satisfaction? Medical Care, 45, 88-94. https://doi.org/10.1097/01.mlr.0000241048.85215.8b

[6] Williams, E., Manwell, L.B., Konrad, T.R. and Linzer, M. (2007) The Relationship of Organizational Culture, Stress, Satisfaction and Burnout with Physician-Reported Error and Suboptimal Care: Results from the MEMO Study. Health Care Management Review, 32, 203-212. https://doi.org/10.1097/01.HMR.0000281626.28363.59

[7] Renzi, C., Tabolli, S., Ianni, A., Di Pietro, C. and Puddu, P. (2005) Burnout and Job Satisfaction Comparing Healthcare Staff of a Dermatological Hospital and a General Hospital. Journal of the European Academy of Dermatology and Venereology, 19, 153-157. https://doi.org/10.1111/j.1468-3083.2005.01029.x

[8] Grembowski, D., Paschane, D., Diehr, P., Katon, W., Martin, D. and Patrick, D.L. (2005) Managed Care, Physician Job Satisfaction, and the Quality of Primary Care. Journal of General Internal Medicine, 20, 271-277. https://doi.org/10.1111/j.1525-1497.2005.32127.x

[9] Wetterneck, T.B., Linzer, M., McMurray, J.E., et al. (2002) Work-Life and Satisfaction of General Internists. SGIM Career Satisfaction Study Group. Archives of Internal Medicine, 162, 649-656. https://doi.org/10.1001/archinte.162.6.649

[10] Williams, E.S., Konrad, T.R., Linzer, M., et al. (2002) Physician, Practice, and Pa- 
tient Characteristics Related to Primary Care Physician Physical and Mental Health: Results from the Physician Work-Life Survey. Health Services Research, 37, 121-143. https://doi.org/10.1111/1475-6773.00007

[11] Carmen, G., Sandra, R., Isabel, R. and Onofre, M. (2000) Family Physician Job Satisfaction in Different Medical Care Organization Models. Family Practice, 17, 309-313. https://doi.org/10.1093/fampra/17.4.309

[12] Alkhalaf, J.H., Singh, R., Malallah, M. and al Jak, E.A. (2009) Job Satisfaction and Stress Level of Primary Health Caregivers at Primary Health Centers in Qatar. The International Journal of Medicine, 2, 245-250.

[13] Al-Juhani, A.M. and Kishk, N. (2006) Job Satisfaction among Primary Health Care Physicians and Nurses in Al-Madinah Al-Munawwara. The Journal of the Egyptian Public Health Association, 81, 165-180.

[14] Mc Bride, M. and Metcalfe, D. (1995) General Practitioners' Low Morale: Reasons and Solutions. British Journal of General Practice, 45, 227-229.

[15] Haas, J.S., Cook, E.F., Puopolo, A.L., Burstin, H.R., Cleary, P.D. and Brennan, T.A. (2000) Is the Professional Satisfaction of General Internists Associated with Patient Satisfaction? Journal of General Internal Medicine, 15, 122-128. https://doi.org/10.1046/j.1525-1497.2000.02219.x

[16] Warr, P.J., Cook, J. and Wall, T. (1979) Scales for the Measurement of Some Work Attitudes and Aspects of Psychological Well-Being. Journal of Occupational Psychology, 52, 129-148. https://doi.org/10.1111/j.2044-8325.1979.tb00448.x

[17] Goldberg, D.P. and Williams, P. (1988) A User's Guide to the General Health Questionnaire. NFER-Nelson, Windsor.

[18] Spickard Jr., A., Gabbe, S.G. and Christensen, J.F. (2002) Mid-Career Burnout in Generalist and Specialist Physicians. JAMA, 288, 1447-1450. https://doi.org/10.1001/jama.288.12.1447

[19] Mohr, D.C., Young, G.J., Meterko, M., Stolzmann, K.L. and White, B. (2011) Job Satisfaction of Primary Care Team Members and Quality of Care. American Journal of Medical Quality, 26, 18-25. https://doi.org/10.1177/1062860610373378

[20] Sibbald, B., Enzer, I., Cooper, C., Rout, U. and Sutherland, V. (2000) GP Job Satisfaction in 1987, 1990 and 1998: Lessons for the Future? Family Practice, 17, 364-371. https://doi.org/10.1093/fampra/17.5.364

[21] Simoens, S., Scott, A. and Sibbald, B. (2002) Job Satisfaction, Work Related Stress and Intentions to Quit of Scottish GPS. Scottish Medical Journal, 47, 80-86. https://doi.org/10.1177/003693300204700403

[22] Harris, M.F., Proudfoot, J.G., Jayasinghe, U.W., et al. (2007) Job Satisfaction of Staff and the Team Environment in Australian General Practice. The Medical Journal of Australia, 186, 570-573.

[23] Sobreques, J., Cebria, J., Segura, J., Rodriguez, C., Garcia, M. and Juncosa, S. (2003) Job Satisfaction and Burnout in General Practitioners. Atención Primaria, 31, 227-233. https://doi.org/10.1157/13044898

[24] Mainous, A.G., Ramsbottom-lucier, M. and Rich, E.C. (1994) The Role of Clinical Workload and Satisfaction with Workload in Rural Primary Care Physician Retention. Archives of Family Medicine, 3, 787-792. https://doi.org/10.1001/archfami.3.9.787

[25] Eker, L., Tuzun, E.H., Daskapan, A. and Surenkok, O. (2004) Predictors of Job Satisfaction among Physiotherapists in Turkey. Journal of Occupational Health, 46, 500-505. https://doi.org/10.1539/joh.46.500 
[26] Bascunan, R.M.L. (2005) Changes in Physician-Patient Relationship and Medical Satisfaction. Revista Medica de Chile, 133, 11-16.

[27] Al-Eisa, I., Al-Mutar, M. and Al-Abduljalil, H. (2005) Job Satisfaction of Primary Health Care Physicians at Capital Health Region, Kuwait. Middle East Journal of Family Medicine, 3, 2-6. 